\title{
Reorganization of language-related neuronal networks in patients with left temporal lobe epilepsy - an fMRI study
}

\author{
M. Brázdil, P. Chlebus, M. Mikl, M. Pažourková, P. Krupa and I. Rektor \\ Departments of Neurology and Neuroimaging, Brno Epilepsy Centre, St Anne's University Hospital, Brno, Czech Republic
}

\begin{abstract}
Keywords:
functional magnetic resonance imaging, language, plasticity, temporal lobe epilepsy, verbal fluency task
\end{abstract}

Received 26 January 2004 Accepted 6 June 2004
To investigate the inter- and intrahemispheric reorganization of the language cortex in left temporal lobe epilepsy (TLE) with left-sided hippocampal sclerosis. A functional magnetic resonance imaging was performed on 13 right-handed patients suffering from medically intractable left TLE, and in 13 sex- and age-matched healthy controls. The activation paradigm used was a silent word generation task. A language laterality index (LI) was calculated from the number of activated voxels in the right and left anterior two-thirds of the hemispheres. Significant differences between the patients and the controls were observed in the activation of the left-sided inferior frontal gyrus. Less consistent findings in this region, as well as the relative protection of Broca's area from the activation, were revealed in the patients. In addition, different patterns of activation were proven in the cerebellum and other cortical as well as subcortical brain structures within both hemispheres. Significant differences were also found in the values of the language LIs between the investigated groups: these values suggested a more bihemispheric language representation in the patients. As anticipated, lateralization of the language functions in the epileptics significantly decreased in connection with an earlier age of initial insult. Our results support the hypothesis of a significant intra- and interhemispheric functional reorganization of language-related neuronal networks in left TLE.

\section{Introduction}

Functional magnetic resonance imaging (fMRI) has been used increasingly in recent years to determine movement and language cortical representation in the pre-surgical evaluation of patients with intractable epilepsy. To prevent postoperative speech difficulties, an accurate defining of language representation is preferentially required in patients with frontal or temporal lobe epilepsy (TLE). Until very recently, hemispheric language dominance has usually been assessed by an intracarotid injection of a short-acting barbiturate with concomitant language testing (Wada test) (Wada, 1949). Recently, a functional MRI was suggested as a potential non-invasive alternative to the Wada test. Previous fMRI studies presented results that were in agreement with Wada language lateralization in both children and adults, in temporal as well as extratemporal epilepsies (Morris et al., 1994; Desmond et al., 1995; Binder et al., 1996; Bahn et al., 1997; Hertz-Pannier et al., 1997; Theodore, 1997; Worthington et al., 1997; Benbadis et al., 1998; Yetkin et al., 1998; Bazin et al., 2000; Lehericy et al., 2000; Gao

Correspondence: Milan Brázdil, Department of Neurology, Brno Epilepsy Centre, St Anne's University Hospital, Brno 656 91, Czech Republic (tel.: + 420543182 639; fax: + 420543182 624;

e-mail: mbrazd@med.muni.cz). et al., 2001; Balsamo and Gaillard, 2002; Adcock et al., 2003; Sabbah et al., 2003). However, different methods and a variety of language tasks have been employed, which may contribute to some conflicting results (Lehericy et al., 2000; Balsamo and Gaillard, 2002). The validation of fMRI methods for determining language lateralization in clinical practice is ongoing. The most frequently applied activation paradigm in studies on language-related brain activation seems to be a silent word generation task (verbal fluency task - VFT). Despite its simplicity, this task was proven to be the most reliably lateralizing one, and it now represents the most frequently utilized task in fMRI studies on global language functions (Benson et al., 1999).

In addition to its ability to accurately determine language lateralization, fMRI can also provide data on intrahemispheric language activation patterns, and thus localize some language areas. These areas may be distributed variably, both within and between the hemispheres. Investigation of intrahemispheric language organization may then be useful in pre-surgical setup as well as in studies on potential cortical reorganization of the epileptic brain. The utility of fMRI for studying neural plasticity has been repeatedly confirmed (Springer et al., 1999; Balsamo and Gaillard, 2002). Using fMRI methodology, apparent language lateralization shifts have been repeatedly observed after strokes in adult patients (Weiller et al., 1993; Thulborn et al., 
1999). Similarly, an obvious postoperative interhemispheric shift of the language-related network to the right side was observed in a serial fMRI study of a hemispherotomized child suffering from Rasmussen's syndrome of the left hemisphere (Hertz-Pannier et al., 2002). One voluminous fMRI study on language dominance in epilepsy revealed a significant association between atypical speech lateralization and an earlier age of seizure onset (Springer et al., 1999). And finally, a more bihemispheric language representation was recently proven in an fMRI analysis of left TLE (Adcock et al., 2003). In concurrence with the results of previously published Wada studies, the above-cited findings have suggested significant interhemispheric speech reorganization in left hemisphere epilepsies (Rausch and Walsh, 1984; Helmstaedter et al., 1997; Risse et al., 1997; Benbadis, 2001; Brázdil et al., 2003; Janszky et al., 2003). However, the impact of epilepsy on the possible intrahemispheric reorganization of language functions has only rarely been investigated using fMRI (Billingsley et al., 2001). As far as we are aware, no fMRI study has yet been published that investigates both the inter- and intrahemispheric reorganization of language brain regions in patients with obvious mesiotemporal epilepsies and hippocampal sclerosis. In our study, we therefore aimed to determine the potential effect of spreading epileptiform activity on both the inter- and intrahemispheric organization of distant language-related neuronal networks.

\section{Methods}

\section{Subjects}

Thirteen right-handed patients suffering from medically intractable left-sided TLE (nine females, four males) and 13 sex- and age-matched healthy, right- handed controls participated in the study. The mean age in the patient group was $37.3 \pm 9.82$ years (with a range from 19 to 53 years; median 40); the mean age in the control group was $36.5 \pm 10.56$ years (with range from 21 to 53 years; median 38). In the patient group, the mean age at the time of seizure onset was $12.4 \pm 11.02$ years (median 11); the mean age of initial insult was $5.7 \pm 10.11$ years (median 0.92 ); and the mean seizure frequency at the time of the investigation was $5.7 \pm 2.46 /$ month (median 5). All of the patients had been routinely investigated within the epilepsy surgery program, including longterm semi-invasive (scalp + sphenoidal electrodes) video-electroencephalogram (EEG) monitoring (in some cases, invasive video-EEG monitoring using depth electrodes), neuropsychological testing, interictal single photon emission computed tomography, and high-resolution MRI. In all of the patients, electrophysiological data suggested an ictal onset zone in the left mesiotemporal region, and the MRI investigation revealed unilateral left-sided hippocampal sclerosis. Nine of the patients underwent a standardized bilateral intracarotid short-acting barbiturate procedure to assess language and memory functions prior to the surgical treatment of their seizures (Table 1). The healthy subjects were volunteers from the professional or academic sector with no history of neurological or psychiatric disease. Informed consent was obtained from each participant after all of the procedures were fully explained, and the study received the approval of the local ethics committee.

Czech was the primary language of all subjects. Handedness was determined according to subject preference for writing and drawing, which was determined by subject report and by direct observation. A more detailed analysis of hand preference was obtained from the Matějček and Žlab (1972) questionnaire.

Table 1 Patient characteristics

\begin{tabular}{cllllllll}
\hline Pt. No & Sex & $\begin{array}{l}\text { Age } \\
\text { (years) }\end{array}$ & $\begin{array}{l}\text { Age of initial } \\
\text { insult (years) }\end{array}$ & $\begin{array}{l}\text { Age of seizure } \\
\text { onset (years) }\end{array}$ & $\begin{array}{l}\text { Seizure } \\
\text { frequency }\end{array}$ & $\begin{array}{l}\text { MRI } \\
\text { finding }\end{array}$ & $\begin{array}{l}\text { Language dominance } \\
\text { as determined by Wada test }\end{array}$ & $\begin{array}{l}\text { Language } \\
\text { laterality index }\end{array}$ \\
\hline 1 & M & 40 & 2 & 26 & $8 / \mathrm{m}$ & HS left & Left & +50.4 \\
2 & F & 19 & 0.4 & 4 & $7 / \mathrm{m}$ & HS left & Left & +23.2 \\
3 & F & 40 & 3 & 3 & $3 / \mathrm{m}$ & HS left & - & +28 \\
4 & M & 35 & 0.1 & 21 & $2 / \mathrm{m}$ & HS left & Left & +10.6 \\
5 & M & 25 & 0.5 & 4 & $8 / \mathrm{m}$ & HS left & Right & +5.9 \\
6 & M & 53 & 11 & 11 & $10 / \mathrm{m}$ & HS left & - & +51.4 \\
7 & F & 32 & 5 & 5 & $7 / \mathrm{m}$ & HS left & Left & +54.2 \\
8 & F & 22 & 0.9 & 1 & $4 / \mathrm{m}$ & HS left & - & +4.1 \\
9 & F & 44 & 0.1 & 23 & $4 / \mathrm{m}$ & HS left & Left & -1.5 \\
10 & F & 43 & 12 & 12 & $5 / \mathrm{m}$ & HS left & Left & +34.5 \\
11 & F & 47 & 0.7 & 0.7 & $5 / \mathrm{m}$ & HS left & - & +67.8 \\
12 & F & 45 & 38 & 38 & $3 / \mathrm{m}$ & HS left & Left & +44.7 \\
13 & F & 40 & 0.3 & 12 & $8 / \mathrm{m}$ & HS left & Right & -19.6 \\
\hline
\end{tabular}

HS, hippocampal sclerosis; MRI, magnetic resonance imaging. 


\section{Activation task}

The subjects were scanned while performing a simple phonemic VFT. The experimental design was an AB 'boxcar' design, with the fluency task (A) alternating with periods of rest (B). Each condition was presented in a block lasting $32 \mathrm{~s}$; five blocks of each condition were performed. In the active block, subjects were required to silently generate as many words as possible beginning with a letter $(\mathrm{I}, \mathrm{J}, \mathrm{N}, \mathrm{O}$, or $\mathrm{P}$ ) that had previously been presented to them binaurally through headphones. During the resting condition, subjects simply relaxed. Instructions with demonstrations were given before scanning. After scanning, participants had to report on their own performances, and say whether they had been successful in generating words.

\section{Image acquisition}

Imaging was performed on a $1.5 \mathrm{~T}$ Siemens Symphony scanner (Erlangen, Germany) equipped with Numaris 4 System (MRease). Prior to the acquisition of the functional data, anatomical T1-weighted images were acquired (32 transversal slices: resolution $256 \times 256$; slice thickness $3.5 \mathrm{~mm}$; $\mathrm{TR}=739 \mathrm{~ms} ; \mathrm{TE}=15 \mathrm{~ms}$; field of view $(\mathrm{FOV})=220 \mathrm{~mm}$; flip angle $90^{\circ}$; total duration $4 \mathrm{~min}, 47 \mathrm{~s}$ ). The functional images were subsequently acquired using a gradient echo, echoplanar imaging (EPI) sequence: TR (scan repeat time) $=$ $4520 \mathrm{~ms} ; \mathrm{TE}=40 \mathrm{~ms} ; \mathrm{FOV}=220 \mathrm{~mm}$; flip angle $90^{\circ}$; matrix size $64 \times 64$; slice thickness $3.5 \mathrm{~mm}$; 32 transversal slices per scan. Each functional study consisted of a time course series of 71 scans and covered the entire brain volume (total duration: $5 \mathrm{~min}, 20 \mathrm{~s}$ ). Following functional measurements, high-resolution anatomical T1-weighted images were acquired using a 3D sequence that served as a matrix for the functional imaging (160 sagittal slices: resolution $512 \times 512$; slice thickness $1.17 \mathrm{~mm} ; \quad \mathrm{TR}=1700 \mathrm{~ms} ; \quad \mathrm{TE}=3.96 \mathrm{~ms} ; \quad \mathrm{FOV}=$ $246 \mathrm{~mm}$; flip angle $15^{\circ}$; total duration $7 \mathrm{~min}, 17 \mathrm{~s}$ ).

\section{fMRI data analysis}

A statistical parametric mapping (SPM99; Wellcome Department of Cognitive Neurology, London, UK) program was used to analyze the fMRI data. The following pre-processing was applied to each subject's time series of fMRI scans: realignment to correct for any motion artefacts; normalization to fit into a standard anatomical space (MNI); spatial smoothing using a Gaussian filter kernel having a full width at half maximum (FWHM) $6 \mathrm{~mm}$; temporal smoothing with hrf filter and high-pass filter of $136 \mathrm{~s}$. The voxel size generated from the above acquisition parameters was oversampled to $3 \times 3 \times 3 \mathrm{~mm}$. The first 12 scans of each time series were skipped in order to reach a steady-state magnetization. Statistical parametric maps were computed to detect activation using a general linear model voxel-wise analysis. Boxcar reference waveform convolved with a kernel that approximates the hemodynamic response curve was used as a regressor of specific effects in the imaging data. Specific hypotheses (activation $>$ rest) were tested with a $t$ value [SPM $(t)]$ at each voxel. The activation maps were superimposed over the high-resolution anatomical images to display the areas of brain activation. Confidence levels of $P<0.001$ uncorrected (to compare activations in predicted areas) and $P<0.05$ corrected for multiple comparisons (to demonstrate unpredicted areas) were used for individual data analysis. Group results were analyzed using a random effect analysis (RFX) with a probability level of 0.0001 (onesample $t$-test to produce representative group results, and two-sample $t$-test to contrast the results between the groups with hypothesis controls $>$ patients).

\section{fMRI laterality index}

Activation volumes were determined in each subject by counting the significantly activated voxels in the anterior two-thirds of each hemisphere. Only supratentorial structures were included for analysis. A laterality index (LI) was calculated for each subject as a ratio $\left[V_{\mathrm{L}}-V_{\mathrm{R}}\right] /$ $\left[V_{\mathrm{L}}+V_{\mathrm{R}}\right] \times 100$, where $V_{\mathrm{L}}$ and $V_{\mathrm{R}}$ are activation volumes for the left and right hemisphere. This approach yields an LI ranging between +100 (strong left hemisphere dominance) and -100 (strong right hemisphere dominance). The LI was classified as indicating a left hemispheric language dominance when LI $>+20$; no dominance when $-20 \leq \mathrm{LI} \leq+20$; or right hemispheric dominance when LI $<-20$ (Springer et al., 1999). A standard statistical procedure ( $t$-test for dependent samples) was used to evaluate group differences in LI between the left TLE patients and the healthy controls. A regression analysis was subsequently used to identify numerical variables (age of initial insult and age of seizure onset) associated with LI in the patient group. If a log-normal distribution of variables was found in the evaluated data, the logarithmic values of the variables were further analyzed. Finally, the results of the regression analysis were validated with Spearman Rank Order Correlations. Statistics were obtained using the routines included in the Statistica program (StatSoft Inc., Tulsa, OK, USA).

\section{Results}

A random effect group analysis for healthy controls revealed the most extensive clusters of significant 
activation within the left-sided inferior frontal gyrus, mainly including Brodmann's areas (BA) 44, 45, and 47. Other less prominent clusters of activation were seen in both sides of the anterior cingulate gyrus, with clear-cut left-sided predominance (BA 32), left-sided middle frontal gyrus (BA 6), left-sided lobulus parietalis inferior (BA 40), and right-sided inferior frontal gyrus (BA 47). Additional areas of activation were observed in the head of the right caudate, in left thalamus, and both sides of the cerebellum with right-sided predominance.

A random effect group analysis for the patients showed less consistent findings. The global maximum of activation was observed in the right-sided inferior frontal gyrus (BA 47). A slightly less significant and mainly less extensive cluster of activation was also found in the left BA 47. In the patient group, atypical activation was revealed within the left-sided inferior frontal gyrus. The relative protection of Broca's area (BA 44, 45) from the activation, in combination with the presence of a higher amount of small activation clusters situated within BA 44, 45, and the premotor cortex (BA 6) represented the most striking findings (Fig. 1). A highly significant cluster of activation was found in the left-sided medial frontal gyrus (BA 6), extending into the right-sided anterior cingulate gyrus (BA 32) and bordered by the medial frontal gyrus (BA 6). Quite extensive activation was also revealed in the basal ganglia - mainly in both sides of the putamen, with more significant findings in the right-sided structures. The number of activated voxels within the left and right subcortical regions was counterbalanced only with inconspicuous left-sided predominance. Discrete activation was also found in the left-sided posterior hippocampus. In comparison with the healthy controls, a surprisingly moderate amount of activation was revealed within the patients' cerebellum (slight left-sided accentuation), which exceeded $P<0.001$ but did not reach a probability level of 0.0001 (uncorrected). Detailed results of random effect group analysis for both the healthy controls and the patients are given in Table 2.

A between-group random effect analysis clearly demonstrated significant differences between the patients and the controls in the pattern of activation within the left-sided inferior frontal gyrus. The most significant finding was observed in Broca's area BA 44 (Talairach coordinates: $x=-48, \quad y=9, \quad z=21$; $t$-score $=4.76 ; z$-score $=3.95)($ Fig. 2). Subtle but still significant differences were further proven in the rightsided middle frontal gyrus (BA 9). Despite obvious differences between patient and control group data within the activation of the cerebellum, anterior cingulate, and subcortical structures, a statistical analysis performed at the probability level of $0.0001 \mathrm{did}$ not prove a significant variance in these regions. Neither were significant differences revealed in two-sample $t$-test contrasting the results between the groups, with a hypothesis of patients $>$ controls.

Significant differences were found in the values of the language LIs between the investigated groups (control group: mean $=35.3 \pm 20.7$, median $=43$; patient group: mean $=27.2 \pm 26.1$, median $=28)(P<0.01)$. As anticipated, the lateralization of the language functions in terms of LI in the epileptics significantly decreased in connection with an earlier age of initial insult $(r=0.63, P<0.05)$. Congruous results were
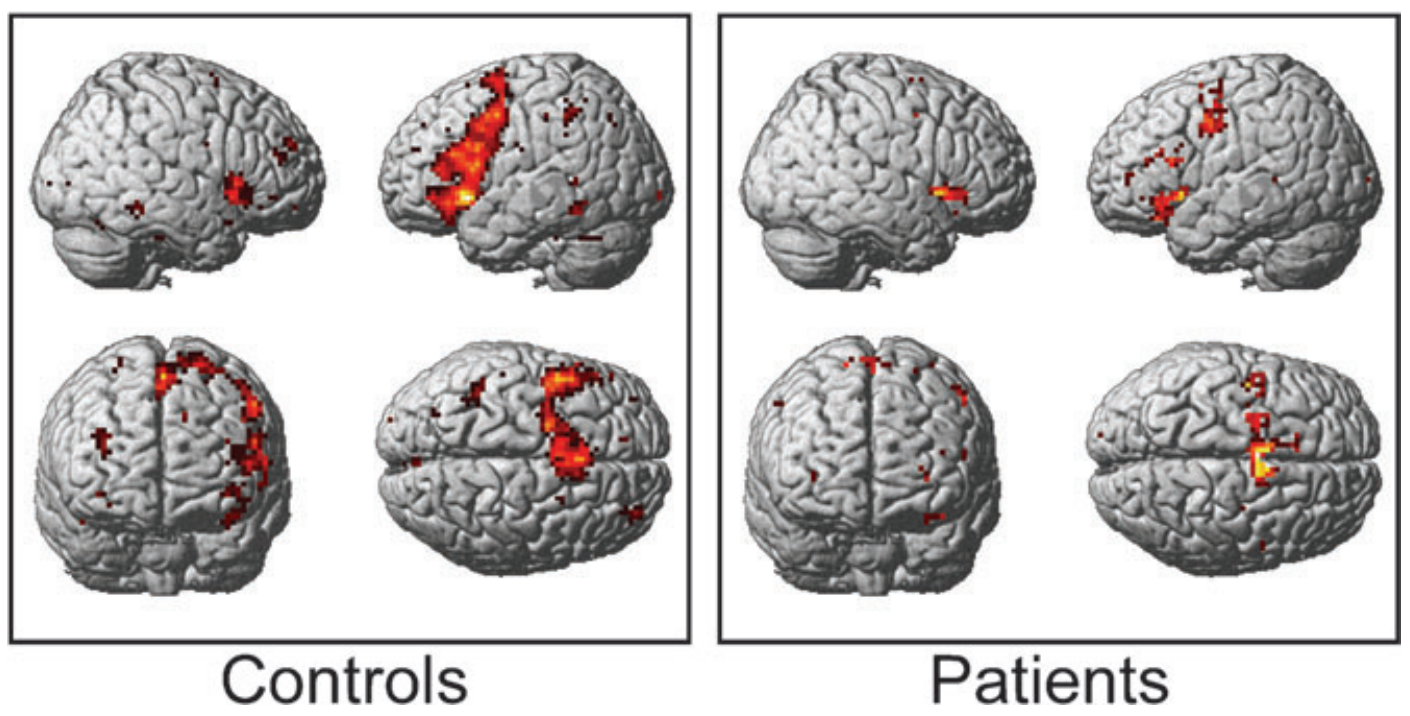

Figure 1 The 3D views of average language activations for 13 epileptic patients and for 13 healthy controls. All activated voxels meet a significance threshold of $P<0.001$ (uncorrected at a voxel level). 
Table 2 Brain areas that showed significant activation in verbal fluency task across 13 controls and 13 patients

\begin{tabular}{|c|c|c|c|}
\hline ROI (Brodmann area) & $\begin{array}{l}\text { MNI coordinates } \\
(x, y, z)\end{array}$ & $\begin{array}{l}\text { Size } \\
\text { (voxels) }\end{array}$ & $\begin{array}{l}t \text {-score/ } \\
z \text {-score }\end{array}$ \\
\hline \multicolumn{4}{|l|}{ Controls } \\
\hline $\begin{array}{l}\text { Left inferior } \\
\text { frontal gyrus }(44,4547)\end{array}$ & $-39,18,-6$ & 577 & $19.9 / 6.41$ \\
\hline Right cerebellum & $24,-63,-27$ & 92 & $12.62 / 5.46$ \\
\hline $\begin{array}{l}\text { Right anterior } \\
\text { cingulate gyrus (32) }\end{array}$ & $-3,21,45$ & 236 & $10.22 / 5.13$ \\
\hline Right caudate & $18,9,18$ & 84 & $9.68 / 5.02$ \\
\hline $\begin{array}{l}\text { Left middle } \\
\text { frontal gyrus (6) }\end{array}$ & $-24,0,63$ & 24 & $9.62 / 5.01$ \\
\hline Left thalamus & $-12,-6,6$ & 17 & $9.50 / 4.98$ \\
\hline Left cerebellum & $-9,-57,-24$ & 83 & $9.38 / 4.96$ \\
\hline $\begin{array}{l}\text { Right inferior } \\
\text { frontal gyrus (47) }\end{array}$ & $33,24,-6$ & 72 & $8.43 / 4.74$ \\
\hline $\begin{array}{l}\text { Left inferior } \\
\text { parietal lobule (40) }\end{array}$ & $-24,-42,39$ & 37 & $7.24 / 4.41$ \\
\hline \multicolumn{4}{|l|}{ Patients } \\
\hline $\begin{array}{l}\text { Right inferior } \\
\text { frontal gyrus (47) }\end{array}$ & $45,12,-3$ & 42 & $9.63 / 5.01$ \\
\hline Right putamen & $21,6,18$ & 37 & $8.56 / 4.77$ \\
\hline Left putamen & $-15,-6,12$ & 43 & $8.53 / 4.76$ \\
\hline $\begin{array}{l}\text { Left medialis } \\
\text { frontal gyrus (6) }\end{array}$ & $-3,-3,60$ & 54 & $8.40 / 4.73$ \\
\hline Left hippocampus & $-30,-27,-6$ & 34 & $7.42 / 4.46$ \\
\hline $\begin{array}{l}\text { Left inferior } \\
\text { frontal gyrus (47) }\end{array}$ & $-30,21,-3$ & 19 & $6.46 / 4.16$ \\
\hline
\end{tabular}

Voxel size $3 \times 3 \times 3 \mathrm{~mm} ; 12$ d.f.; $t$ and $z$ scores from the most significant voxel in regions of interest (ROI).

The activations were significant at $P<0.0001$ uncorrected. Extent threshold $k=10$ voxels.

also obtained from a non-parametric Spearman test $(r=0.64, P=0.018)$. In contrast, LI was not significantly correlated with the age of seizure onset $(r=$ $-0.12, P>0.05)$. The age of initial insult versus LI scatterplot is shown in Fig. 3.

\section{Discussion}

The study of brain functional plasticity and cortical reorganization represents an increasingly animated issue in contemporary neuroscience research. It has been repeatedly proven that epilepsy could be viewed as a model disease for studying plasticity-dependent changes in cortical representation. Many previously published papers have revealed an unusually high incidence of atypical hemispheric language dominance in epileptic patients, which was more frequently associated with the presence of left hemisphere seizure focus and a younger age at the time of seizure onset (Branch et al., 1964; Rasmussen and Milner, 1977; Loring et al., 1990; Helmstaedter et al., 1997; Risse et al., 1997; Springer et al., 1999; Benbadis, 2001). These findings clearly suggested a possible connection between epilepsy (in terms of underlying epileptiform activity) and the development of left hemisphere language dominance, which may have resulted in a reorganization of language functions. Using Wada procedures and later fMRI methods, atypical language representation was also more frequently revealed in patients suffering from left-sided TLE (Rausch and Walsh, 1984; Thivard et al., 2002; Adcock et al., 2003; Brázdil et al., 2003; Sabbah et al., 2003). TLE studies thus additionally support the influential impact of epileptic seizures or subclinical epileptiform activity, spreading from the left mesiotemporal structures, on the functional organization of speech. In the study of a suggested 'disruptive effect of spreading epileptiform activity on the cortical association areas' (Rausch and Walsh, 1984), fMRI methodology clearly prevails over Wada testing, particularly because of its ability to provide data on intrahemispheric language activation patterns. Unfortunately the published fMRI studies on TLE patients have been primarily focused on evaluating the plasticity-dependent interhemispheric shift of speech functions (Van der Kallen et al., 1998; Thivard et al., 2002; Adcock et al., 2003; Sabbah et al., 2003). To our knowledge, there has not yet been a study of both interand intrahemispheric reorganization of language brain regions in patients with unequivocal mesiotemporal epilepsies.

As in previous studies, the fMRI results of this study clearly support the capability of epileptic seizures or subclinical epileptiform activity, arising from the left amygdalohippocampal complex, to significantly interfere with the development of language-related neuronal networks. The most impressive difference between our epileptic patients and the healthy controls - significantly different activation of Broca's area, with relative preservation of BAs 44 and 45 from activation in epileptic patients - represents a key finding that most likely reflects a disturbance in the early organization of this primary speech area in left TLE subjects. Nevertheless, from the viewpoint of plasticity-dependent changes in speech organization, the observation of subtle but significant differences in activation within the right middle frontal gyrus seems to be equally important. During the experimental task, our patients lacked activation within this region. This finding may reflect a more extensive reorganization of the language-related neuronal networks, extending throughout both hemispheres. The hypothetical network reorganization seems to be supported by other our observations. A different activation pattern within the basal ganglia in the patients - an obviously more distinctive activation of both sides of the putamen with left-sided predominance in the number of activated voxels - might indicate the hypothetical extension of the language-related neuronal 

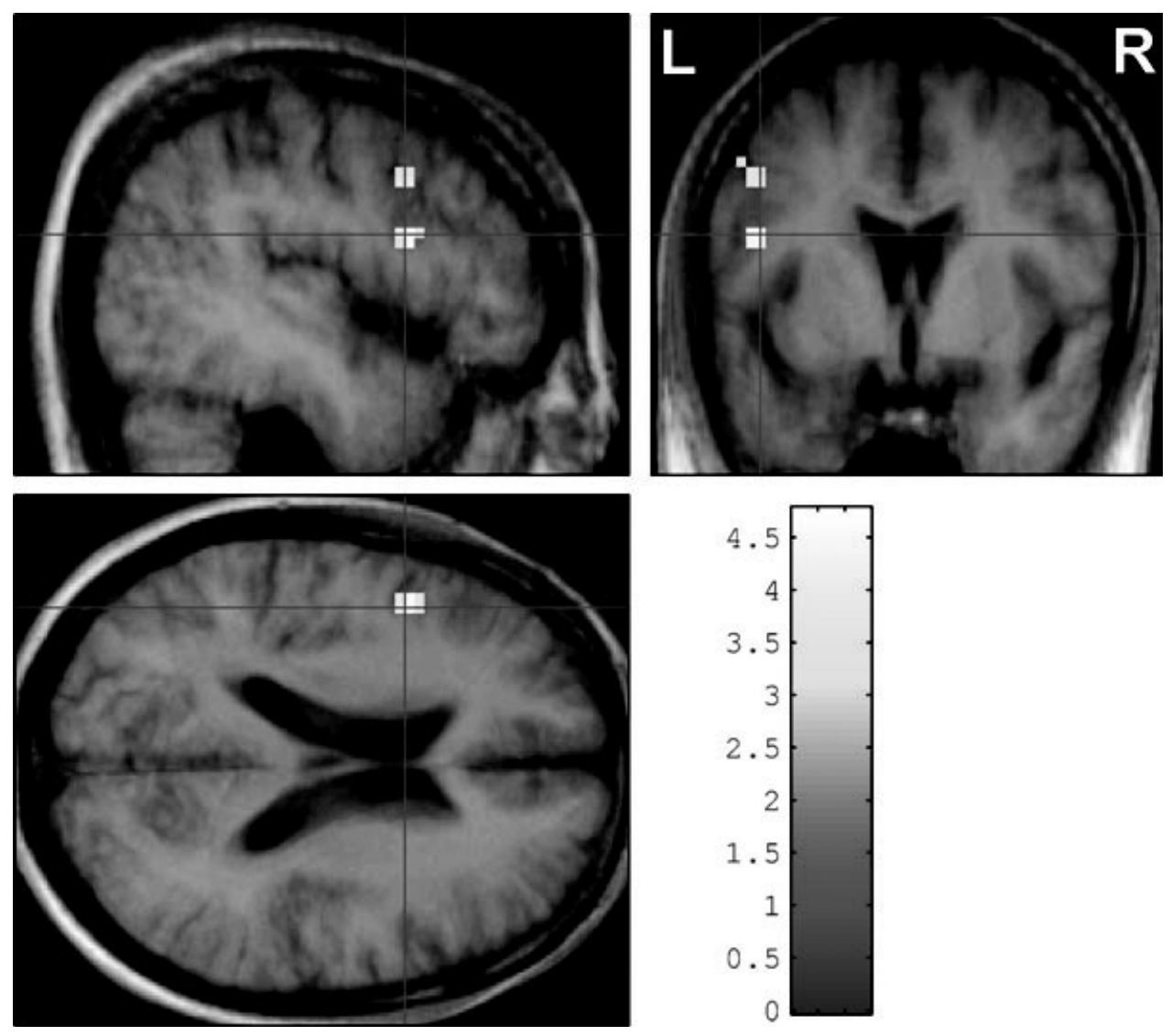

Figure 2 Significant differences in left inferior frontal gyrus activation between healthy subjects and temporal lobe epilepsy patients. Significance threshold $P<0.001$ uncorrected. Talairach's coordinates are given in text.

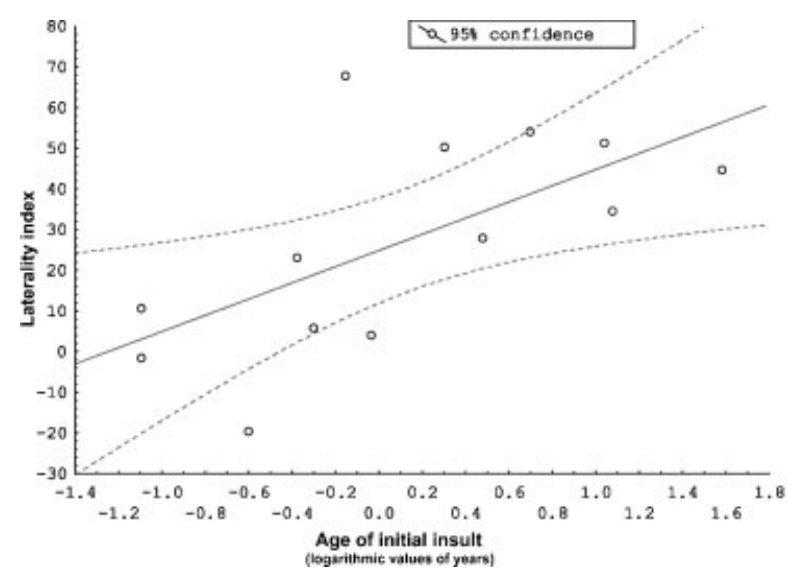

Figure 3 Scatterplot of language laterality index as a function of age at initial insult in the group of left temporal lobe epilepsy patients, including the regression line.

network within the left hemisphere. The left-sided accentuation of cerebellar activation patterns observed in our epileptic patients again represents atypical finding in VFT studies, and can therefore be viewed as a presumed consequence of the pathological development of the discussed neurocognitive network. Finally, the global maximum of activation in the patient group was observed within the right-sided inferior frontal gyrus, which could represent the preferential involvement of the right-sided part of the pre-existing bilateral language networks (Weiller et al., 1995; Thulborn et al., 1999).

It must be emphasized that despite obvious differences between the patient and control group data in the activation within the anterior cingulate, cerebellum, and subcortical structures, a statistical analysis performed at the probability level of 0.0001 did not prove significant variance in these regions. Because of the analogous lack of significant differences in two-sample $t$-tests contrasting the results between the groups with the hypothesis of patients > controls, speculations can be made about a complex, highly individual mode of speech reorganization, and a significant interindividual variance in the anatomical targets for shifting language functions. In such a case, the between-group random effect analysis will inevitably fail in the effort to describe integral components of the reorganized languagerelated neuronal networks. 
On the contrary, different results between both groups in terms of the activation within different brain areas must be interpreted very cautiously. Despite our cautious efforts to create a control group as conformed as possible to the patient group (ratio of males/females, mean age, range and median of age, all right-handers), important differences remain. One of these differences with a theoretical impact on the results can be seen in the different education levels of the two groups. It could be that more educated control group might have used different word-generating techniques than the epilepsy patients, and this difference then might contribute to some distinctions in a between-group comparison. In our opinion, it is hard to imagine that all the betweengroup differences found in our study could be explained by different word-generating technique, as these techniques are interindividually highly variable. Nevertheless, future studies on this topic should probably include a more thorough control of subject performance.

In our evaluation of group LIs, we proved significant differences between the patient group and the healthy control group. The patient group had clearly weaker left language dominance, and thus a more bihemispheric language representation, than the control group. In accordance with our results, significantly different LIs were recently revealed between the healthy controls and the left TLE patients in analogously composed studies with 8-12 left TLE patients (Thivard et al., 2002; Adcock et al., 2003). In contrast, language lateralization in right-handed male and female left TLE patients was not significantly different from that of healthy right-handed volunteers in the first fMRI study focused on this issue (Van der Kallen et al., 1998). The reason for contradictory results in this study can be found in the small sample size bias $(n=5)$ and/or in a different approach to calculating the LT. For deeper insight into the connection between left TLE and the language lateralization, an analysis of the relationship between LIs and the age of initial insult in our patients provided quite helpful data. As anticipated, lateralization of speech functions significantly decreased with an earlier age of initial insult. Nevertheless, it should be mentioned that in three of our patients (pts 6, 10, 12) a rather late initial insult was detected. Some literature indicates that a late initial insult (i.e. after the age of 4 years) rarely leads to hippocampal damage (Sagar and Oxbury, 1987). Indeed, in these cases it cannot be completely excluded that another, unknown early childhood injury led to the development of hippocampal sclerosis. On the contrary, the high LI values in all of these subjects supports the assumption of no disturbance of speech development during first years of their lives. The observed trend thus supports the direct impact of early epileptic dysfunction within the left temporal lobe on the pathologic adaptive shift of language functions to the right hemisphere (Rausch and Walsh, 1984; Devinski et al., 1993; Adcock et al., 2003; Brázdil et al., 2003).

From the present study, it seems obvious that functional organization of the language-related neuronal network is significantly modified in patients suffering from left mesiotemporal epilepsy. In addition to the evaluation of the discussed interhemispheric compensatory shift of the language functions, the proof of significant plasticity-dependent intrahemispheric speech reorganization may be obtained from fMRI studies. The negative impact of spreading epileptiform activity from the mesiotemporal regions on the early development in targeted cortical sites should be considered as the most likely pathogenetic mechanism of these findings.

\section{Acknowledgements}

The study was supported by Research Project MŠMT ĆR 281101 . The authors wish to express their thanks to Ms Anne Johnson for her assistance in the preparation of the manuscript.

\section{References}

Adcock JE, Wise RG, Oxbury JM, Oxbury SM, Matthews PM (2003). Quantitative fMRI assessment of the differences in lateralization of language-related brain activation in patients with temporal lobe epilepsy. NeuroImage 18:423438.

Bahn MM, Lin W, Silbergeld DL et al. (1997). Localization of language cortices by functional MR imaging compared with intracarotid amobarbital hemispheric sedation. $A m J$ Roentgenology 169:575-579.

Balsamo LM, Gaillard WD (2002). The utility of functional magnetic resonance imaging in epilepsy and language. Curr Neurol Neurosci Rep 2:142-149.

Bazin B, Cohen L, Lehericy S et al. (2000). Study of hemispheric lateralization of language regions by functional MRI. Validation with the Wada test. Rev Neurol (Paris) 156: $145-148$.

Benbadis SR (2001). Intracarotid amobarbital test to define language lateralization. In: Lüders HO, Comair YG, eds. Epilepsy surgery, 2nd edn. Lippincott Williams \& Wilkins, Philadelphia, pp. 525-529.

Benbadis SR, Binder JR, Swanson SJ et al. (1998). Is speech arrest during Wada testing a valid method for determining hemispheric representation of language? Brain Lang 65:441446.

Benson RR, Fitzgerald DB, LeSueur LL et al. (1999). Language dominance determined by whole brain functional MRI in patients with brain lesions. Neurology 52:798-809.

Billingsley RL, McAndrews MP, Crawley AP, Mikulis DJ (2001). Functional MRI of phonological and semantic processing in temporal lobe epilepsy. Brain 124:12181227. 
Binder JR, Swanson SJ, Hammeke TA et al. (1996). Determination of language dominance using functional MRI: a comparison with the Wada test. Neurology 46:978-984.

Branch C, Milner B, Rasmussen T (1964). Intracarotid sodium amytal for the lateralization of cerebral speech dominance. J Neurosurg 21:399-405.

Brázdil M, Zákopčan J, Kuba R, Fanfrdlová Z, Rektor, I (2003). Atypical hemispheric language dominance in left temporal lobe epilepsy as a result of the reorganization of language functions. Epilepsy \& Behavior 4:414-419.

Desmond JE, Sum JM, Wagner AD et al. (1995). Functional MRI measurement of language lateralization in Wadatested patients. Brain 118:1411-1420.

Devinski O, Perrine K, Llinas R, Luciano DJ, Dogali M (1993). Anterior temporal language areas in patients with early onset of temporal lobe epilepsy. Ann Neurol 34:727732.

Gao X, Jiang C, Lu C, Shen T (2001). Determination of the dominant language hemisphere by functional MRI in patients with temporal lobe epilepsy. Chin Med J (Engl) 114:711-713.

Helmstaedter C, Kurthen M, Linke DB, Elger CE (1997). Patterns of language dominance in focal left and right hemisphere epilepsies: relation to MRI findings, EEG, sex, and age at onset of epilepsy. Brain Cogn 33:135-150.

Hertz-Pannier L, Gaillard WD, Mott SH et al. (1997). Noninvasive assessment of language dominance in children and adolescents with functional MRI: a preliminary study. Neurology 48:1003-1013.

Hertz-Pannier L, Chiron C, Jambaque I et al. (2002). Late plasticity for language in a child's nondominant hemisphere: a pre- and post-surgery fMRI study. Brain 125:361372 .

Janszky J, Jokeit H, Heinemann D, Schulz R, Woermann FG, Ebner A (2003). Epileptic activity influences the speech organization in medial temporal lobe epilepsy. Brain 126:2043-2051.

Lehericy S, Cohen L, Bazin B et al. (2000). Functional MR evaluation of temporal end frontal language dominance compared with the Wada test. Neurology 54:1625-1633.

Loring DW, Meador KJ, Lee GP et al. (1990). Cerebral language lateralization: evidence from intracarotid amobarbital testing. Neuropsychologia 28:831-838.

Matějček Z, Žlab Z (1972). Zkouska laterality (T116). Psychodiagnostika, Bratislava.

Morris GL, Mueller WM, Yetkin FZ et al. (1994). Functional magnetic resonance imaging in partial epilepsy. Epilepsia 35:1194-1198.

Rasmussen T, Milner B (1977). The role of early brain injury in determining lateralization of cerebral speech functions. Ann NY Acad Sci 299:355-369.
Rausch R, Walsh GO (1984). Right-hemisphere language dominance in right-handed epileptic patients. Arch Neurol 41:1077-1080.

Risse GL, Gates JR, Fangman MC (1997). A reconsideration of bilateral language representation based on the intracarotid amobarbital procedure. Brain Cogn 33:118-132.

Sabbah P, Chassoux F, Leveque C et al. (2003). Functional MR imaging in assessment of language dominance in epileptic patients. NeuroImage 18:460-467.

Sagar HJ, Oxbury JM (1987). Hippocampal neuron loss in temporal lobe epilepsy: correlation with early childhood convulsions. Ann Neurol 22:334-340.

Springer JA, Binder JR, Hammeke TA et al. (1999). Language dominance in neurologically normal and epilepsy subjects. A functional MRI study. Brain 122:2033-2045.

Theodore WH (1997). Detection of language lateralization in epilepsy with functional MRI. Neurol Network Commentary 1:144-146.

Thivard L, Léhericy S, Cohen L et al. (2002). Functional reorganisation of language areas in temporal lobe epilepsy: a fMRI study. Epilepsia 43(Suppl. 8):162.

Thulborn KR, Carpenter PA, Just MA (1999). Plasticity of language-related brain function during recovery from stroke. Stroke 30:749-754.

Van der Kallen BFW, Morris GL, Yetkin FZ, van Erning LJTO, Thijssen HOM, Haughton VM (1998). Hemispheric language dominance studied with functional MR: preliminary study in healthy volunteers and patients with epilepsy. Am J Neuroradiol 19:73-77.

Wada J (1949). A new method for the determination of the side of cerebral speech dominance. A preliminary report on the intra-carotid injection of sodium amytal in man. Medical Biology 14:221-222.

Weiller C, Ramsay SC, Wise RJ, Friston KJ, Frackowiak RS (1993). Individual patterns of functional reorganization in the human cerebral cortex after capsular infarction. Ann Neurol 33:181-189.

Weiller C, Isensee C, Rijntjes M et al. (1995). Recovery from Wernicke's aphasia: a positron emission tomographic study. Ann Neurol 37:723-732.

Worthington C, Vincent DJ, Bryant AE et al. (1997). Comparison of functional magnetic resonance imaging for language localization and intracarotid speech amytal testing in presurgical evaluation for intractable epilepsy. Preliminary results. Stereotact Funct Neurosurg 69:197-201.

Yetkin FZ, Swanson S, Fischer M et al. (1998). Functional MR of frontal lobe activation: comparison with Wada language results. Am J Neuroradiol 19:1095-1098. 